\title{
Temporal changes in intracranial pressure in a modified experimental model of closed head injury
}

\author{
Koen Engelborghs, M.D., Jan Verlooy, M.D., Ph.D., Jos Van Reempts, \\ Bruno Van Deuren, Mies Van de Ven, and Marcel Borgers, Ph.D. \\ Department of Neurosurgery, University Hospital Antwerp, Antwerp, Belgium; and Department of Life \\ Sciences-Neuropathology, Janssen Research Foundation, Beerse, Belgium
}

\begin{abstract}
Object. The authors describe an experimental model of closed head injury in rodents that was modified from one developed by Marmarou and colleagues. This modification allows dual control of the dynamic process of impact compared with impulse loading that occurs at the moment of primary brain injury. The principal element in this weight-drop model is an adjustable table that supports the rat at the moment of impact from weights positioned at different heights (accelerations). The aim was to obtain reproducible pathological intracranial pressure (ICPs) while maximally reducing the incidence of mortality and skull fractures.

Methods. Intracranial pressure was investigated in different experimental settings, including two different rat strains and various impact-acceleration conditions and posttrauma survival times. Identical impact-acceleration injuries produced a considerably higher mortality rate in Wistar rats than in Sprague-Dawley rats (50\% and 0\%, respectively). Gradually increasing severity of impact-acceleration conditions resulted in findings of a significant correlation between the degree of traumatic challenge and increased ICP at 4 hours $\left(\mathrm{p}<0.001, \mathrm{R}^{2}=0.73\right)$. When the impact-acceleration ratio was changed to result in a more severe head injury, the ICP at 4,24 , and 72 hours was significantly elevated in comparison with that seen in sham-injured rats (4 hours: $19.7 \pm 2.8 \mathrm{~mm} \mathrm{Hg}, \mathrm{p}=0.004$; 24 hours: $21.8 \pm 1.1 \mathrm{~mm} \mathrm{Hg}$, $\mathrm{p}=0.002 ; 72$ hours: $11.9 \pm 2.5 \mathrm{~mm} \mathrm{Hg}, \mathrm{p}=0.009)$. Comparison of the rise in ICP between moderate and severe impactacceleration injury at 4 and 24 hours revealed a significantly higher value after severe injury ( 4 hours: $p=0.008 ; 24$ hours: $p=0.004)$. Continuous recordings showed that ICP mounted very rapidly to peak values, which declined gradually toward a pathological level dependent on the severity of the primary insult. Histological examination after severe trauma revealed evidence of irreversible neuronal necrosis, diffuse axonal injury, petechial bleeding, glial swelling, and perivascular edema.

Conclusions. This modified closed head injury model mimics several clinical features of traumatic injury and produces reliable, predictable, and reproducible ICP elevations with concomitant morphological alterations.
\end{abstract}

\section{KEY WORDS - traumatic brain injury - intracranial pressure • experimental model • neurotrauma • diffuse axonal injury • histological study $\bullet$ rat}

$\mathrm{T}$ RAUMATIC brain injury (TBI) initiates a broad range of complex mechanical and pathophysiological destructive cascades and hence is associated with high mortality and morbidity rates. In blunt head trauma, primary brain injury results in focal or diffuse damage. Secondary events inflicted on an already ravaged brain may be even more detrimental to its function than the initial insults. Despite progressive improvements in the management of severe head trauma throughout the years, neurotrauma remains a serious public health problem. In the United States each year more than 2,000,000 individuals present at hospitals with a head injury. Of these, approximately 75,000 die, 2000 live in a vegetative state, 500 develop epileptic seizures, and another 125,000 endure lifelong debilitating loss of function. ${ }^{10} \mathrm{~A}$ study conducted by the Traumatic Coma Data Bank study group revealed that approximately $55 \%$ of patients who were comatose on admission suffered from diffuse brain injury. ${ }^{15} \mathrm{Al}-$ though considerable and profound research efforts as well as clinical investigations have been conducted, the standard guidelines ${ }^{2}$ concerning the treatment of severe head injury have not changed substantially compared with measures recommended a decade ago.

Several groups of investigators have developed animal models of TBI in an attempt to reproduce various aspects of the pathophysiological responses, neurological syndromes, and histopathological findings observed in human head injury. ${ }^{13}$ Two reciprocal hypotheses are implicit in brain injury modeling: 1) that TBI in humans can be duplicated in nonhumans; and 2) that TBI in nonhuman models replicates human injury. ${ }^{8}$ Among the plethora of experimental models, the most commonly used are closed head injury and percussion models. The latter preferentially produce a focal brain contusion. ${ }^{16}$ Artifacts resulting 
from the experimental methodology (for example, blood pressure surge and craniotomy) not only complicate the findings, but they also show biomechanical differences with most common clinical trauma cases. Therefore, a closed head injury impact-acceleration model ${ }^{7,14}$ was chosen and modified to allow adjustment of the dynamic impact-acceleration process, including variations in impact loading (contusion) and impulse loading (concussion). We reasoned that limitation of the extraneous influences inherent to the experimental methodology, as well as the conceptual approximation, should make the model more reliable and reproducible and hence might improve its clinical relevance. In analogy with the clinical situation, the severity of brain damage was estimated by using intracranial pressure (ICP) measurements performed at different time intervals after various impact-acceleration traumas. Furthermore, an absolute prerequisite in this model besides a rise in ICP is the presence of morphological alterations comparable to those encountered in clinical neuropathology. Finally, the model aimed to reduce the mortality rate and skull fractures as much as possible. Preliminary results of this study were published in the proceedings of the 10th Brain Edema Congress. ${ }^{6}$

\section{Materials and Methods}

Animal housing and treatment conditions complied with European Union directive for Animal Welfare No. 86/609.

\section{Trauma Device}

The trauma device is composed of two elements (Fig. 1). The upper part is a hollow plexiglass column with an inner diameter of $20 \mathrm{~mm}$ and a length of $1.5 \mathrm{~m}$. The column is perforated at regular intervals to permit initiation of weight drops from various heights. It contains a segmented stainless steel cylinder with an outer diameter of $19 \mathrm{~mm}$, which was constructed to allow stepwise weight variations between 50 and $500 \mathrm{~g}$. Once released, the steel cylinder falls freely by gravity. A nylon string that passes through a smooth central aperture of a metal lid fixed to the top of the plexiglass tube supports the cylinder. A slightly deformable silicone disc $9 \mathrm{~mm}$ in diameter and $2 \mathrm{~mm}$ thick is attached to the impact side of the cylinder. An automatic security device is provided at the bottom to prevent rebound impact of the cylinder. The whole setting is firmly fixed to a horizontal base and precisely leveled.

The second element is a rigid plastic horizontal platform $(10 \times$ $30 \mathrm{~cm}, 475 \mathrm{~g}$ ) mounted on replaceable springs of variable elasticity. The movable platform is assembled in a plexiglass chamber in which six springs are asymmetrically positioned to allow a vertical downward displacement of the entire horizontal platform after impact. A stereotactic apparatus is mounted on the plexiglass chamber to allow accurate positioning of the rat. To permit acceleration of the head after the initial blow, the stereotactic headframe is removed before impact. To eliminate lateral twisting of the animal's head after removing the stereotactic apparatus or during impact-acceleration trauma, two soft foam cushions mounted on mobile rods support the lateral sides of the head. The interaural line is used as a reference coordinate to focus the impact at a level between $-3 \mathrm{~mm}$ and $+6 \mathrm{~mm}$ from the bregma in the rostrocaudal axis according to Paxinos and Watson. ${ }^{19}$ In the lateral axis, earbar markers are used to center the impact. Because the head is supported by this stiff platform, critical hyperextension of the neck during impact-acceleration trauma is avoided. The rat is secured on the platform by means of three 5-cm-wide Velcro strips.

\section{Induction of Head Trauma}

Male Wistar or Sprague-Dawley rats weighing between 340 and $380 \mathrm{~g}$ that were allowed access to food and water (12/12-hour day-night cycle) underwent standard anesthesia induction over 4
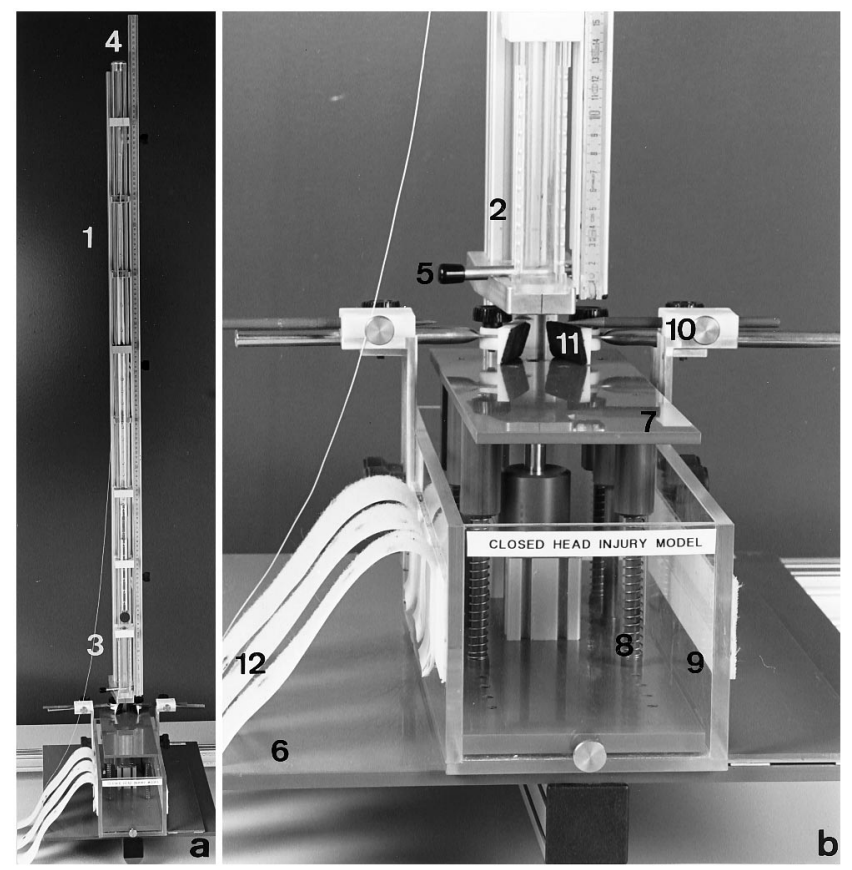

FIG. 1. Photographs showing the head injury device (a) and detail of the horizontal platform (b). The upper part consists of a hollow plexiglass column (1) perforated at regular intervals (2) to permit weight drops from various heights. The weight (3) is fixed by means of a nylon string, which passes through a smooth central aperture of a metal lid (4). An automatic security device (5) is provided at the bottom to prevent rebound impact of the cylinder. The whole apparatus is firmly fixed to a horizontal base (6) and precisely leveled. b: Detail of the rigid plastic horizontal platform (7) mounted on replaceable springs of variable elasticity (8) assembled in a plexiglass chamber (9). At both sides of the chamber, a stereotactic apparatus (10) and two soft foam cushions (11) are attached to allow accurate positioning of the rat. Three velcro strips (12) are used to secure the animal on the platform.

minutes with halothane $(4 \%)$ in a mixture of nitrous oxide $(70 \%)$ and oxygen (30\%). They were rapidly intubated and positioned on the horizontal platform with the aid of a stereotactic device. The positioning procedure was performed with the animals receiving 1 to $1.5 \%$ halothane. Exactly 9 minutes after induction, anesthesia was stopped and the horizontal platform was placed directly under the lower end of the plexiglass column. Within 10 seconds, an impact-acceleration trauma was produced on the animal's unprotected skull by a weight dropped from a predetermined height.

During the whole procedure the animals remained intubated. After impact-acceleration trauma, the rats were closely observed and the endotracheal tube was removed when recovery was adequate, that is, when spontaneous breathing and righting response were restored. Apneic rats were mechanically ventilated with free air for a maximum of 30 minutes at 70 beats per minute and a tidal volume of $3 \mathrm{ml}$. Blood and mucus were aspirated when necessary. During and after recovery the rats were placed in individual cages and allowed free access to food and water.

\section{Monitoring Parameters}

To measure ICP, a 2-mm burr hole was drilled into the right interparietal plate of the rat's skull at a point $4 \mathrm{~mm}$ from the midline and $2 \mathrm{~mm}$ caudal to the bregma suture. A microsensor probe $(1.2 \mathrm{~mm}$ diameter) attached to a micromanipulator was inserted in the cortical parenchyma with the sensor facing toward the midline. In a frontal plane, the probe was placed below a $70^{\circ}$ angle to avoid perforation of the lateral ventricle. All ICP measurements were ob- 
TABLE 1

Outcome in two rat strains 4 hours after impactacceleration trauma*

\begin{tabular}{lccccc}
\hline \hline \multicolumn{1}{c}{ Strain } & $\begin{array}{c}\text { No. of } \\
\text { Rats }\end{array}$ & $\begin{array}{c}\text { Skull } \\
\text { Fracture }\end{array}$ & Death & Apnea & $\begin{array}{c}\text { Convul- } \\
\text { sions }\end{array}$ \\
\hline Wistar & 10 & 5 & 5 & 9 & 2 \\
Sprague-Dawley & 10 & 4 & 0 & 5 & 1 \\
\hline
\end{tabular}

* Pilot experiment: impact-acceleration settings were $400 \mathrm{~g}, 60 \mathrm{~cm}, \mathrm{k}=$ $2206 \mathrm{~N} / \mathrm{m}$

tained while the animals were receiving the halothane anesthetic $(1-1.5 \%)$. The right femoral artery was cannulated for blood pressure monitoring and arterial blood gas sampling. Body temperature was monitored by means of a rectal probe and maintained at $36.5^{\circ} \mathrm{C}$ with the aid of a heating pad. All physiological data were continuously recorded on a two-channel recorder and digitally stored via a personal computer.

\section{Pilot Trials}

After several preliminary experiments in which the optimum impact height, weight of the metal cylinder, diameter and hardness of the silicon tip, positioning of the rats, and stiffness of the horizontal platform were determined, a standard methodology was defined. To select the most appropriate rat strain, the consequences of an impact-acceleration trauma $(400 \mathrm{~g}$ at $60 \mathrm{~cm})$ on ICP, fracture threshold, and mortality rates were compared between Wistar and Sprague-Dawley rats at 4 hours postinjury (10 animals/strain). In addition, ICP levels were determined in Sprague-Dawley rats at 4 hours after $400 \mathrm{~g}$ impacts from 25-, 40-, and 55-cm heights, respectively, in comparison with a sham injury (six rats/group). A 400-g weight drop from a height of $47 \mathrm{~cm}$ on a platform adjusted to a stiffness of $\mathrm{k}=2206 \mathrm{~N} / \mathrm{m}$ was selected and is hereafter referred to as moderate impact-acceleration trauma.

\section{Moderate Compared With Severe Challenge}

In this series of experiments, the impact-acceleration challenge was augmented. The weight was kept constant at $400 \mathrm{~g}$ but the impact height was increased to $70 \mathrm{~cm}$ and the stiffness of the table was reduced by adjustment of the spring resistance $(\mathrm{k}=1290 \mathrm{~N} / \mathrm{m})$. We anticipated that this would result mathematically in a more severe impact-acceleration trauma with the emphasis on higher acceleration forces. This setting is hereafter referred to as severe impactacceleration trauma. Under these conditions, ICP was studied in 18 Sprague-Dawley rats (six rats/group) at 4, 24, and 72 hours after severe trauma and compared with that found in sham-injured animals (six rats). In a parallel experiment, the ICP increase after moderate trauma was compared with severe trauma at identical time intervals (4 and 24 hours, six rats/group).

\section{Continuous ICP Recording}

To study the evolution of ICP changes, pressures were continuously recorded during 4 hours after moderate and severe trauma (six rats per group) compared with sham-injured animals (three rats). The ICP measurements started as early as 5 minutes after the initial impact. Blood pressure was monitored before, during, and after the insult. Throughout the entire procedure, rats were anesthetized with $1 \%$ halothane.

\section{Histopathological Studies}

At the end of the experimental procedure all rats subjected to severe trauma conditions $(4,24$, and 72 hours) were killed for histological studies. Anesthesia was interrupted and the animal's chest was rapidly opened. Prior to intracardiac perfusion-fixation, $0.2 \mathrm{ml}$ heparin $(5000 \mathrm{U} / \mathrm{ml})$ was injected into the left ventricle. A catheter was then introduced into the left ventricle, followed by clamping of the descending aorta and incision of the right atrium. A $4 \%$ phos- phate-buffered formaldehyde solution was perfused at room temperature over a period of 5 minutes. Perfusion pressure was maintained at $120 \mathrm{~mm} \mathrm{Hg}$. The brains were subsequently immersionfixed in the same fixative. Coronal vibratome sections $(200 \mu \mathrm{m})$ were prepared under stereotactic guidance. To avoid possible probeinduced artifacts, only morphological changes observed in the left hemisphere were interpreted. Three areas of interest (cortex, hippocampus, and thalamus) were selected and routinely embedded in Epon. Light microscopic studies were performed on 2- $\mu \mathrm{m}$ sections stained with toluidine blue. Electron microscopic studies were performed on ultrathin sections from selected areas.

\section{Statistical Analysis}

Statistical computations were performed using a commercially available software package for exact statistical inference. A twosided Wilcoxon-Mann-Whitney rank-sum test was used for analysis among the various experimental groups. Two-sided probability values of less than 0.05 were regarded as statistically significant. Unless otherwise stated, the reported values are expressed as the mean \pm the standard error of the mean (SEM).

\section{Sources of Supplies and Equipment}

The drill used to create burr holes (Elco Plus model E9818E) was obtained from W \& H Denthalwerk, Bürmoos GmbH, Bürmoos, Austria. The microsensor (ICP Neuro) was purchased from Codman \& Shurtleff, Inc., Randolph, MA, and the micromanipulator (model DKI962; Ultra Precise Small Animal Stereotaxic) from Kopf Instruments, Düsseldorf, Germany. The blood pressure monitor (Argon Transducer) was acquired from Maxxim Medical, Athens, TX, and the blood gas monitor (model ABL 300; Radiometer a/S. 72) was purchased from Emdrudvey Copenhagen N. V., Copenhagen, Denmark. The two-channel recorder (Flatbed Recorder model LR102) was obtained from Yokogawa Europe B.V., Amersfoort, The Netherlands. The software package for exact statistical inference (StatXact 3 for Windows) was purchased from Cytel Software Corp., Cambridge, MA. The MacLab interface (MacLab/8 MK3 Version 3.2.7) was acquired from ADInstruments, Castle Hill, New South Wales, Australia. The light microscope (model DMRBE) was purchased from Leica Mikroskopie, Wetzlar, Germany, and the electron microscope (model CM-100) from Philips, Eindhoven, The Netherlands.

\section{Results}

\section{Pilot Experiments}

As shown in Table 1, when exposed to similar impactacceleration conditions, Wistar rats had a considerably higher mortality rate (five of 10 rats) when compared with Sprague-Dawley rats (no deaths). We found that death was caused mainly by respiratory failure. In the majority of cases, respiratory failure was caused by the development of severe pulmonary edema or direct biomechanical brainstem trauma leading to persistent apnea. An apneic period was observed in nine Wistar and in five SpragueDawley rats. There was no difference in the duration of these periods between groups (3-38 seconds). The skull fracture incidence was equal between groups (five fractures in the Wistar group, four in the Sprague-Dawley rats). In the Wistar group, mortality incidence was well correlated with the presence of skull fractures. In the Sprague-Dawley group, in which there were no deaths, the occurrence of skull fractures coincided with the highest ICPs. Furthermore, in the four animals in which a skull fracture was detected, an apneic period was observed. There was no difference in ICP measured at 4 hours in surviving rats of either strain (Wistar: $21.8 \pm 1.8 \mathrm{~mm} \mathrm{Hg}$; Sprague-Dawley: $19.9 \pm 1.2 \mathrm{~mm} \mathrm{Hg}$; Fig. 2). Two Wistar 


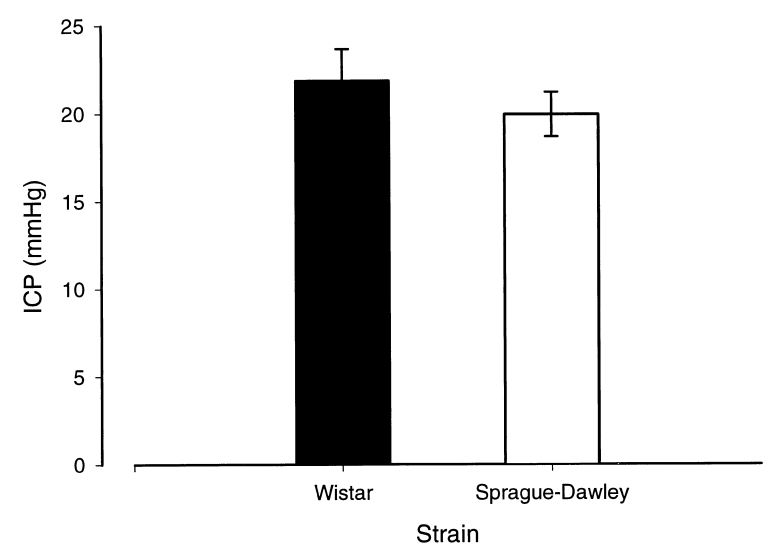

FIG. 2. Bar graph showing increase in ICP in Wistar and Sprague-Dawley rats at 4 hours after similar impact-acceleration trauma (400 g, $60 \mathrm{~cm}, \mathrm{k}=2206 \mathrm{~N} / \mathrm{m}$; mean $\pm \mathrm{SEM}, 10$ rats/group).

and one Sprague-Dawley rat showed mild generalized convulsions starting shortly after impact. In the Wistar rats the convulsions lasted for 11 and 30 seconds, respectively, compared with 3 seconds in the Sprague-Dawley rat.

Gradually increasing impact-acceleration conditions resulted in a significant correlation between the severity of traumatic challenge and an increase in ICP in SpragueDawley rats at 4 hours (slope of ICP/height $=4.9[ \pm 0.74]$ $+[ \pm 0.02] \mathrm{mm} \mathrm{Hg} / \mathrm{cm}, \mathrm{p}<0.001 ; \mathrm{R}^{2}=0.73 ;$ Fig. 3). Skull fractures or apneic periods were absent in both the shaminjured and the $25-\mathrm{cm}$ weight-drop group. As expected, there were no deaths in these groups. In the $40-\mathrm{cm}$ weightdrop group, one rat died at 4 hours as a result of anesthesia problems. In the 55-cm weight-drop group, five of six rats had a closed linear skull fracture at the level of the bregma and two rats died within 8 minutes after trauma. In the 40-cm group two rats exhibited an apneic period of 3 seconds. The apneic period in the $55-\mathrm{cm}$ group lasted for 2 to 7 seconds in five of six rats (Table 2).

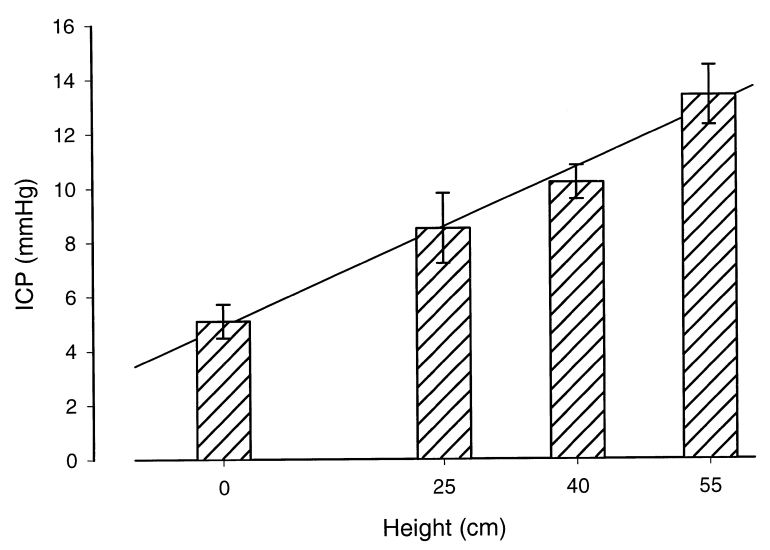

FIG. 3. Bar graph showing measurements obtained 4 hours after gradually increasing impact-acceleration challenge (height $=0-55$ $\mathrm{cm}, 400 \mathrm{~g}, \mathrm{k}=2206 \mathrm{~N} / \mathrm{m}$ ) that showed a significant correlation between the severity of traumatic challenge and a rise in ICP in Sprague-Dawley rats (slope of ICP/height $=4.9 \pm 0.02 \mathrm{~mm}$ $\mathrm{Hg} / \mathrm{cm}, \mathrm{p}<0.001 ; \mathrm{R}^{2}=0.73$; six rats/group, mean $\left.\pm \mathrm{SEM}\right)$.
TABLE 2

Outcome in Sprague-Dawley rats 4 hours after gradually increasing impact-acceleration conditions*

\begin{tabular}{ccccc}
\hline \hline Challenge & $\begin{array}{c}\text { No. of } \\
\text { Rats }\end{array}$ & $\begin{array}{c}\text { Skull } \\
\text { Fracture }\end{array}$ & Death & Apnea \\
\hline sham injury & 6 & 0 & 0 & 0 \\
$25 \mathrm{~cm}, 400 \mathrm{~g}$ & 6 & 0 & 0 & 0 \\
$40 \mathrm{~cm}, 400 \mathrm{~g}$ & 6 & 1 & 1 & 2 \\
$55 \mathrm{~cm}, 400 \mathrm{~g}$ & 6 & 5 & 2 & 5 \\
\hline
\end{tabular}

$* \mathrm{k}=2206 \mathrm{~N} / \mathrm{m}$

\section{Moderate Compared With Severe Challenge}

When the impact-acceleration challenge was augmented (severe trauma), the increase in ICP was again significantly different at 4 hours $(19.7 \pm 2.8 \mathrm{~mm} \mathrm{Hg} ; \mathrm{p}=0.004)$ in comparison with sham-injured rats $(5.5 \pm 0.2 \mathrm{~mm} \mathrm{Hg}$; Fig. 4). This situation was identical at 24 hours $(21.8 \pm$ $1.1 \mathrm{~mm} \mathrm{Hg} ; \mathrm{p}=0.002)$ and 72 hours $(11.9 \pm 2.5 \mathrm{~mm} \mathrm{Hg}$; $p=0.009)$. One rat in the 4-hour and one in the 24-hour group had closed linear skull fractures. These rats also demonstrated the highest ICP in their group (26.5 and 26 $\mathrm{mm} \mathrm{Hg}$, respectively). One rat died in the 4-hour group, and in the 72-hour group two rats did not survive for the required time period and the four surviving animals were severely cachectic. There were no deaths in the 24-hour group. Four hours after severe trauma, there was a significant lowering of the mean arterial blood pressure ([MABP]; $76.6 \pm 3.8 \mathrm{~mm} \mathrm{Hg} ; \mathrm{p}=0.004$ ) in comparison with the initial MABP $(94.9 \pm 3.3 \mathrm{~mm} \mathrm{Hg})$ recorded in sham-injured rats (Table 3). A comparable decrease in MABP was also observed at 24 hours $(86.6 \pm 2.2 \mathrm{~mm} \mathrm{Hg}$; $p=0.056)$. The MABP was restored 72 hours after severe trauma $(91.5 \pm 4.6 \mathrm{~mm} \mathrm{Hg} ; \mathrm{p}=0.45)$. The cerebral perfusion pressure (CPP) showed a comparable pattern; that is, at 4 hours there was a pronounced lowering of CPP $(56.9 \pm 1.6 \mathrm{~mm} \mathrm{Hg} ; \mathrm{p}=0.004)$. A tendency to normalization was seen at 24 hours $(64.8 \pm 2.8 \mathrm{~mm} \mathrm{Hg} ; \mathrm{p}=$ $0.004)$. Although at 72 hours MABP was normalized, CPP remained decreased $(79.6 \pm 2.3 \mathrm{~mm} \mathrm{Hg} ; \mathrm{p}=0.038)$ in comparison with sham-injured rats $(89.6 \pm 3 \mathrm{~mm} \mathrm{Hg})$.

Comparison of ICP values at 4 and 24 hours after moderate compared with severe trauma impact-acceleration also revealed a significantly increased ICP in the severe trauma group (4 hours: $p=0.009 ; 24$ hours: $p=0.004$, Fig. 5). This confirms findings of the pilot experiments, in which a correlation was indicated between ICP and the severity of the TBI challenge.

\section{Continuous ICP Recordings}

Continuous ICP measurement after moderate trauma revealed an abrupt rise in pressure that slowed down to a stable pathological level within approximately 55 minutes $(\mathrm{p}=0.023)$. The ICP pattern appeared similar after severe trauma, although there was a shift toward higher values over the subsequent 4 hours $(p=0.012$; Fig. 6). The initial MABP values were comparable (104.3 \pm 3.4 $\mathrm{mm} \mathrm{Hg}$ ). After impact leading to severe trauma, a brief increase in MABP was noticed within 2 to 3 seconds $(106 \pm 6.9 \mathrm{~mm} \mathrm{Hg} ; \mathrm{p}=0.34)$, followed by a relatively constant decline over the next 17 seconds after impact 


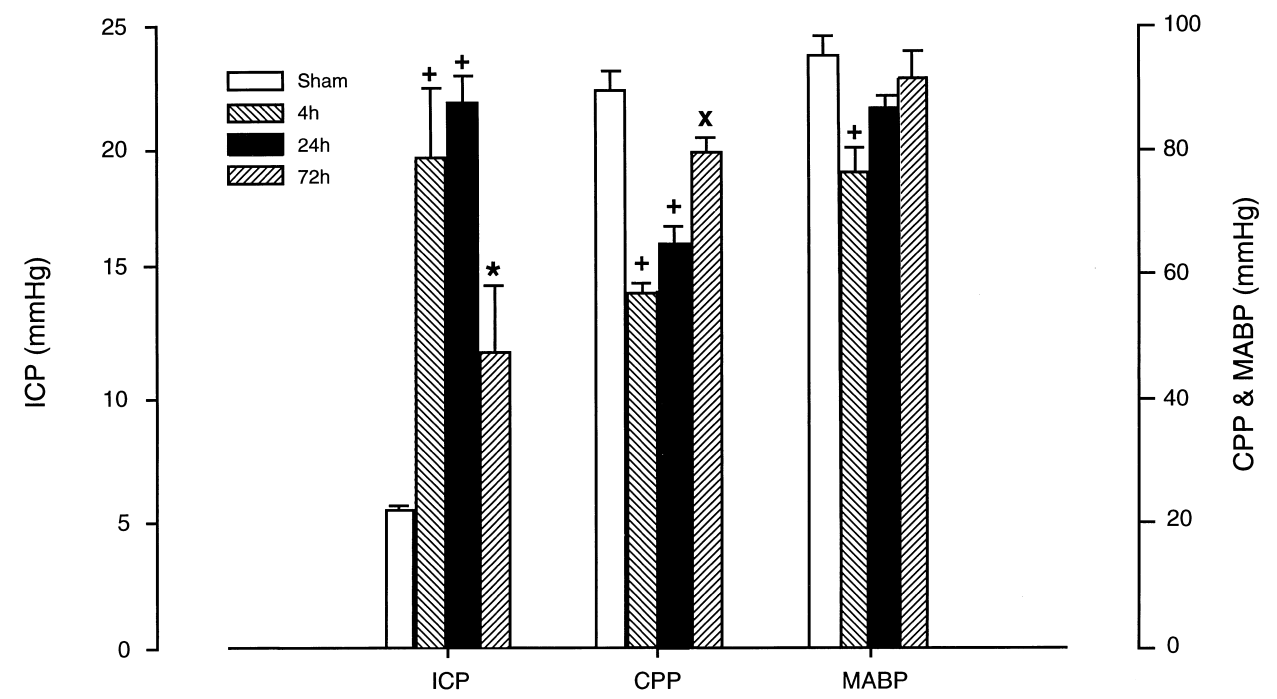

FIG. 4. Bar graph showing changes in ICP, CPP, and MABP at different times after severe impact-acceleration injury in comparison with sham-injured rats (mean $\pm \mathrm{SEM}$; six rats/group; ${ }^{\mathrm{p}} \mathrm{p}<0.005 ;{ }^{*} \mathrm{p}<0.01 ;{ }^{\mathrm{x}} \mathrm{p}<0.05$ ).

$(69.5 \pm 4.1 \mathrm{~mm} \mathrm{Hg} ; \mathrm{p}<0.001$; Fig. 7 upper $)$. Thereafter, MABP gradually recovered to baseline values after 50 to 55 minutes $(96.6 \pm 2.2 \mathrm{~mm} \mathrm{Hg} ; \mathrm{p}=0.17$; Fig. 7 lower $)$. Four hours after head injury, MABP was significantly lower in comparison with preinjury values $(84.4 \pm 4.2$ $\mathrm{mm} \mathrm{Hg} ; \mathrm{p} \mathrm{=} \mathrm{0.014).} \mathrm{Other} \mathrm{physiological} \mathrm{variables} \mathrm{mea-}$ sured before and in the 4 hours after injury are presented in Table 4.

\section{Histopathological Findings}

Macroscopic observation of the entire brain after moderate trauma showed only small hemorrhagic contusions bilaterally at the base of the frontal lobe. In some animals a mild subarachnoid hemorrhage (SAH) was present in the basal cistern and the cisterna magna. Intraventricular hemorrhages were infrequently observed. After severe trauma, focal or contusion lesions were absent, with the exception of those observed at the base of both frontal lobes. In some animals these basofrontal hemorrhagic contusions could be defined as burst lobes. Subarachnoid bleeding was present in almost all rats, although the extent of SAH varied among the animals. However, in most cases, the cisterna magna and basal cisterna were consistently filled with blood. Whenever a massive SAH was present, the blood extended as a thin layer into the subarachnoid space of both cerebral hemispheres.

TABLE 3

Outcome in Sprague-Dawley rats at different time periods after severe trauma

\begin{tabular}{lccccc}
\hline \hline Challenge & $\begin{array}{c}\text { No. of } \\
\text { Rats }\end{array}$ & Survival & $\begin{array}{c}\text { Skull } \\
\text { Fracture }\end{array}$ & Death & Apnea \\
\hline sham injury & 6 & $4 \mathrm{hrs}$ & 0 & 0 & 0 \\
$70 \mathrm{~cm}, 400 \mathrm{~g}$ & 6 & $4 \mathrm{hrs}$ & 1 & 1 & 6 \\
$70 \mathrm{~cm}, 400 \mathrm{~g}$ & 6 & $24 \mathrm{hrs}$ & 1 & 0 & 4 \\
$70 \mathrm{~cm}, 400 \mathrm{~g}$ & 6 & $72 \mathrm{hrs}$ & 0 & 2 & 6 \\
\hline
\end{tabular}

Whereas no structural damage was found in shaminjured animals, histological changes were already obvious 4 hours after severe trauma (Fig. 8a and b). The thalamic nuclei, reticular tract, internal capsule, and optic tract were most vulnerable. Although not very extended, the observed lesions showed a characteristic morphological appearance. At 4 hours small edematous foci were found in the medial thalamus. Neurons in these areas were dense and the majority of them contained pyknotic nuclei. Glial cells were dilated and their swollen cell processes surrounded neurons as well as microvessels. The latter

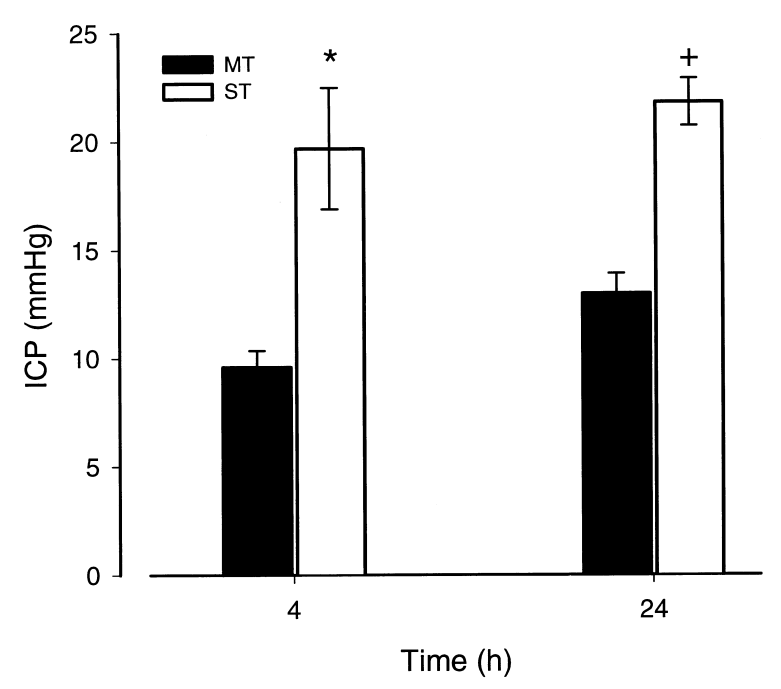

FIG. 5. Bar graph comparing ICP values at 4 and 24 hours after moderate trauma (MT) and severe trauma (ST) and showing a significantly higher ICP in the severe trauma group (mean $\pm \mathrm{SEM}$; six rats/group; ${ }^{*} \mathrm{p}=0.009 ;{ }^{+} \mathrm{p}=0.004$ ). 


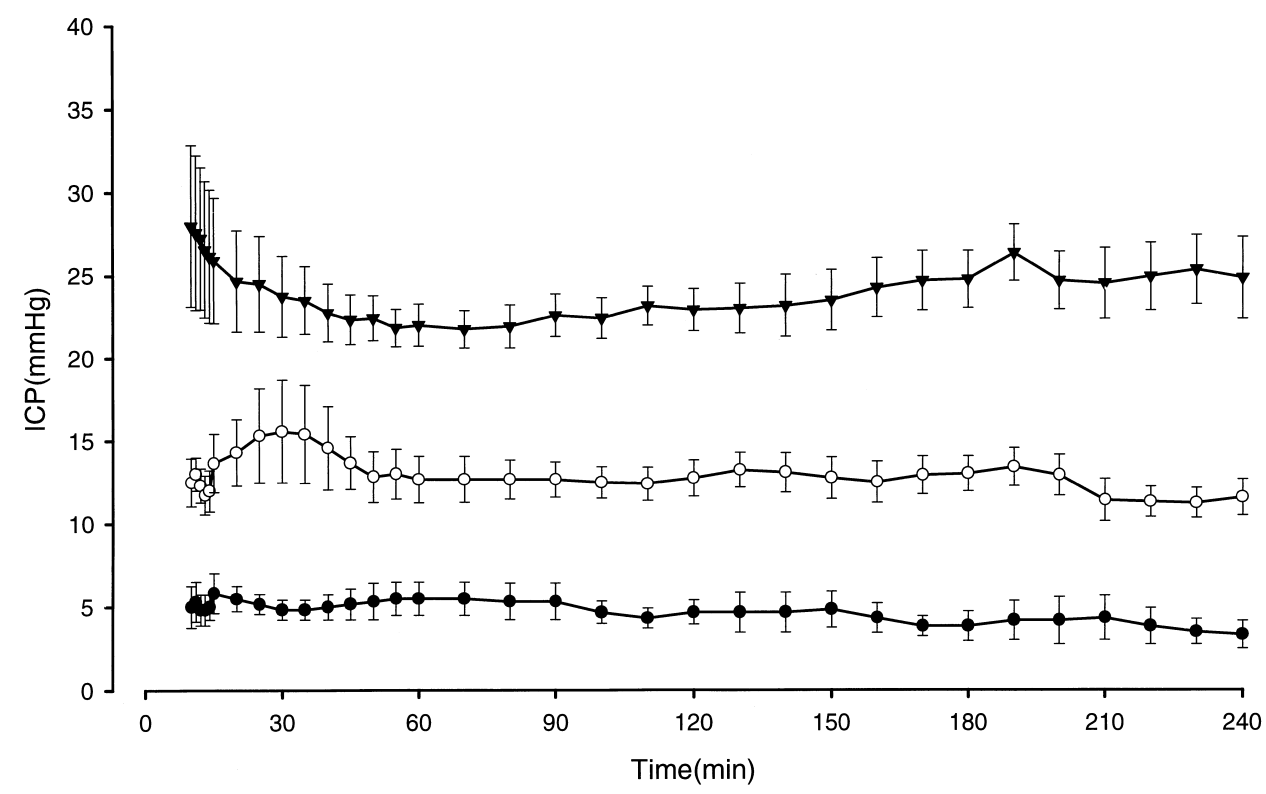

FIG. 6. Graph showing continuous ICP recordings (mean \pm SEM) during 4 hours in rats subjected to moderate (open circles; six rats) and severe impact-acceleration trauma (closed triangles; six rats) compared with sham-injured rats (closed circles; three rats).

were collapsed and contained residual erythrocytes. Diffuse axonal injury (DAI), which was characterized by severe ballooning of axonal processes, was randomly dispersed in the white matter fascicles of the thalamus, in the reticular tract, the internal capsules, and the optic tract. After 24 and 72 hours, edematous spots were less frequently seen, whereas axonal injury became more pronounced (Fig. 8c-e). Petechial hemorrhages were diffusely located throughout both hemispheres and the corpus callosum. At the base of both hemispheres in some of the animals small "contre-coup" lesions as well as interhemispheric gliding contusions could be detected. The irreversible nature of the lesions were confirmed on electron microscopy (Fig. 9).

\section{Discussion}

In this report we describe a modified experimental closed head injury model capable of producing a reliable, predictable and pathological ICP in Sprague-Dawley rats in association with characteristic morphological changes. Because the model provides several major features seen after human traumatic injury, it can be regarded as clinically relevant. Compared with other closed head injury models, this one offers some advantages, such as control over the balance between impact loading andimpulse loading, as well as the capacity to accurately locate the contact area and the resulting stress wave in the brain tissue and skull. Similar to the original pure diffuse brain injury model of Marmarou, et al., ${ }^{14}$ a lethal closed head injury can be achieved without the predominant brainstem damage usually seen in direct dural-impact models. ${ }^{4}$

\section{Closed Head Injury in Rats}

In the last decades, numerous investigators have devel- oped animal models to study TBI. Two major approaches in brain injury modeling have emerged and include closed head injury impact-acceleration models and percussion models. The latter preferentially produce a focal brain contusion $^{3,5,8}$ and biomechanical findings only partially correspond with those encountered in human closed head injury ${ }^{4,23}$ Furthermore, at high levels of injury, fluid-percussion injury is primarily a model of brainstem trauma. ${ }^{22}$ Because these models produce mainly a focal lesion, brain edema is predominately located near the injury site. Moreover, the presence of morphologically damaged axons, or DAI, is rather limited. Although percussion experiments can be regarded as valid brain injury models, a closed head injury impact-acceleration model was chosen and modified to allow adjustment of the dynamic impact-acceleration process, such as variable-impact loading (contusion) and impulse loading (concussion). The relative contribution of either contusive or concussive forces in primary brain injury is limited in this model. Thus, highimpulse loadings will always be associated with "serious" impact loadings, whereas an impact loading alone (for example, on an immobile platform) is dependent exclusively on the strength of the skull and the location of the impact. Furthermore, the inertial loading necessary to produce DAI is related to brain mass. Animals with small brains can tolerate much greater rotational and acceleration/deceleration forces than nonhuman primates and humans. ${ }^{18}$ However, the excessively high acceleration forces that are imperative to induce diffuse brain damage are not required when these forces result from a preceding impact loading, as is demonstrated in the original model and in our modification. Recent head injury studies have demonstrated that in real world accidents, these high levels of inertial forces only occur when an impact force strikes the head or the face; that is, a combination of contact and inertial phenomena. Possibly, the preceding stress wave low- 

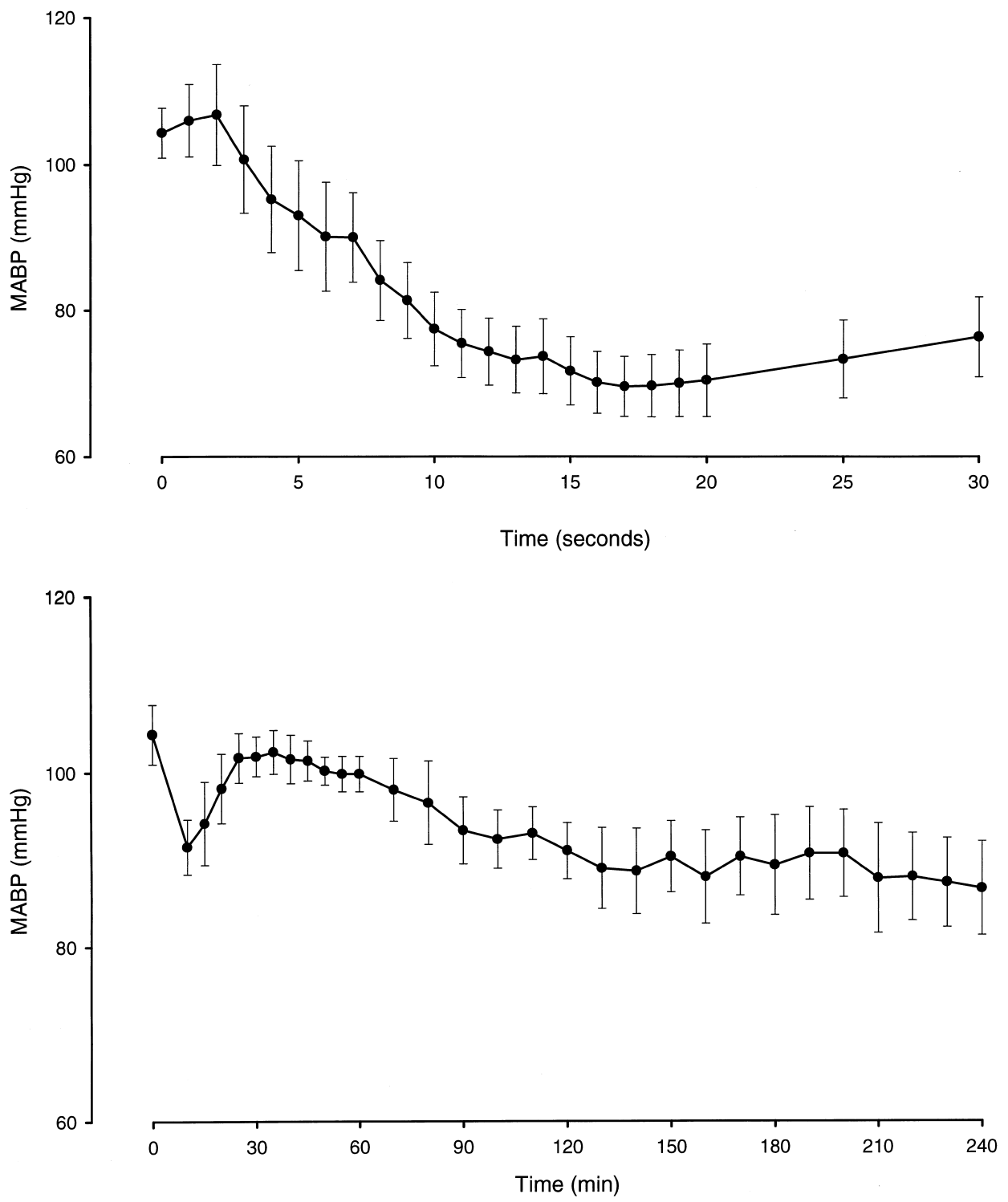

FIG. 7. Graphs showing MABP response at different times after severe impact-acceleration trauma. Upper: The MABP response over the first 30 seconds. A brief increase lasting 2 to 3 seconds $(106 \pm 6.9 \mathrm{~mm} \mathrm{Hg} ; \mathrm{p}=0.34)$ is followed by a relatively constant decline over the next 17 seconds $(69.5 \pm 4.1 \mathrm{~mm} \mathrm{Hg} ; \mathrm{p}<0.001)$. There is no indication of a hypertensive surge (mean \pm SEM; six rats). Lower: The MABP course over 4 hours after severe impact-acceleration trauma. The MABP gradually recovers to baseline values $(104.3 \pm 3.4 \mathrm{~mm} \mathrm{Hg})$ within 50 to 55 minutes $(96.6 \pm$ $2.2 \mathrm{~mm} \mathrm{Hg} ; \mathrm{p}=0.17$ ). Four hours after head injury MABP is significantly lower in comparison with preinjury values $(84.4 \pm 4.2 \mathrm{~mm} \mathrm{Hg} ; \mathrm{p}=0.014)$.

ers the tolerance of the brain parenchyma to acceleration forces. It is well documented that whenever two or more vector forces, such as rotational and translational acceleration, act upon the brain mass, the resulting diffuse brain damage is more pronounced in frequency as well as severity. 8,17 However, in impact-acceleration models both applied forces are manifested in the same sagittal plane. Thus, it can be proposed that the impact component resulting in a stress/strain wave might cause a compressioninduced rotation and/or stretching of the neuronal network. Because this phenomenon occurs simultaneously with the impact, it can be regarded as the first vector force that is rapidly followed by an acceleration force, that is, the second vector force.

\section{Analysis of the Weight-Drop Model}

In our model, the reliability and reproducibility of the impact-acceleration trauma are dependent on the performance of three crucial mechanical components. First, there is the initial impact velocity of the falling weight, which represents the total amount of energy delivered to 
TABLE 4

Physiological variables measured in six Sprague-Dawley rats for 4 hours after severe trauma*

\begin{tabular}{|c|c|c|c|c|c|}
\hline \multirow[b]{2}{*}{ Variable } & \multirow[b]{2}{*}{ Pretrauma Value } & \multicolumn{4}{|c|}{ Posttrauma } \\
\hline & & $1 \mathrm{Hr}$ & $2 \mathrm{Hrs}$ & $3 \mathrm{Hrs}$ & $4 \mathrm{Hrs}$ \\
\hline $\mathrm{pH}$ & $7.40(7.33-7.47)$ & $7.34(7.27-7.39)$ & $7.34(7.25-7.39)$ & $7.35(7.27-7.39)$ & $7.38(7.31-7.39)$ \\
\hline $\mathrm{PO}_{2}$ & $154(122-169)$ & $98.8(89.1-113.5)$ & $96(87.2-113.5)$ & $97.1(91-119.5)$ & $94.5(91.3-122)$ \\
\hline $\mathrm{PCO}_{2}$ & $29.9(20.5-37.5)$ & $47(44-55.8)$ & $43(27.1-69.8)$ & $34(26.1-56.8)$ & $48.5(37-56)$ \\
\hline $\mathrm{HCO}_{3}$ & $18.6(12.6-23)$ & $26.5(24.6-28.8)$ & $23.5(16.8-28.8)$ & $18.9(15.7-27.4)$ & $27.8(22.3-28.9)$ \\
\hline
\end{tabular}

* Numbers in parentheses indicate the range of values.

the skull, and which depends heavily on regular replacement of the nylon thread that holds the cylindrical weight and on avoiding abrasion of the inner plexiglass column, as reported by Piper, et al. ${ }^{21}$ The latter could not be detected in our device, even after daily use for more then 1.5 years. Second, there is the deformation of the silicone impactor, which allows a better adaptation to the convexity of the rat skull at the moment of impact, resulting in a better dispersion of the total amount of kinetic energy (impact velocity) delivered to the head. Third, there is the physical and mechanical behavior of the horizontal platform. A detailed mathematical analysis of the closed head injury model, including impact velocity, peak acceleration, duration of acceleration, and vertical displacement of the platform, performed in collaboration with the Technical University of Eindhoven, The Netherlands, provided insight into the reproducibility of these parameters $(\mathrm{F}$ Sauren, unpublished results).

\section{Mortality and Fracture Threshold of the Rat Skull}

In this model, mortality can be defined on the one hand as pure impact-related death, that is, resulting from direct mechanical brainstem trauma or impact fractures with eventual epidural bleeding. On the other hand mortality can be regarded as acceleration-related death, that is, epidural or subdural hematomas and diffuse vascular injury. To a lesser extent, asphyxia secondary to the development of severe pulmonary edema caused death within 10 minutes after neurotrauma. Direct brainstem trauma caused by a critical hyperextension of the neck led to persistent apnea and usually was accompanied by severe convulsions and cardiac arrhythmias. We learned that when rats did not regain spontaneous breathing after 15 minutes of mechanical ventilation, recovery or even survival was extremely rare. Surviving rats exhibited signs of morbidity after head trauma, consisting of symptoms such as postponed arousal from anesthesia; sluggish, wide-gaited mobility; decreased activity (seeking behavior); and diminished water and food intake.

\section{Diffuse Brain Damage}

Diffuse brain damage is a characteristic feature of primary brain injury following a closed head trauma. It is believed that early death is usually attributable to brain damage secondary to untreatable intracranial hypertension. Likewise, accumulating evidence shows that the final morbidity (persistent vegetative state, disabilities) is determined predominantly by the severity of DAI sepa- rately from the instantaneous loss of cerebral function. Not until recently could this important pattern of brain injury be studied. ${ }^{14}$ In our modified model, as in the original model of Marmarou, et al., ${ }^{14}$ DAI is widely present. Diffuse axonal injury is most likely to occur when the head is loaded with a pure inertial force against a soft object, such as foam. In this respect the intensity of DAI is greater in the Marmarou model. In that model, the rodent head is allowed to move freely after impact, whereas in our model, the movement of the table determines the acceleration of the head. Moreover, the relatively higher mass of the horizontal platform, the lower impact velocity, and the silicon tip substantially reduce the delivered inertial force on the rat's head. Finally, the observed differences between humans and rats in the location of DAI throughout the brain can be explained partially by significant difference in the orientation of the neuraxis (curved compared with linear), the gross anatomy of the brain (gyrencephalic compared with lissencephalic), and the characteristics of the skull. ${ }^{12}$

\section{Intracranial Pressure}

In this modified impact-acceleration model, two interesting features associated with increases in ICP emerge. First, the measured increase in ICP varies linearly with the traumatic challenge, and second, ICP almost instantaneously reaches pathological levels. Whereas a posttraumatic rise in ICP in the subacute and late phase can be accounted for as primarily due to an accumulation of mainly cellular edema, the sudden increase in ICP immediately after head injury might require another explanation. Pfenninger, et al., ${ }^{20}$ have shown that approximately one third of all patients with severe head injury are admitted to the hospital with an increase in ICP of more than 20 to 25 $\mathrm{mm} \mathrm{Hg}$. For obvious reasons, information about the time course of the ICP in the acute phase is lacking. Experimental findings in animal studies may help to fill this gap of information. In our model, the ICP was immediately elevated toward severe pathological levels, which amounted to five- to 10 -fold the normal ICP values. In addition, the time period of the extreme ICP elevation almost equals the episode of unconsciousness in the rats. Gennarelli, et al., ${ }^{9}$ observed similar increases in ICP immediately after acceleration of the head in experiments that induced DAI and traumatic coma. In a sheep impactacceleration model,,$^{12}$ a threefold acute increase in ICP was seen. After fluid-percussion trauma in piglets, ${ }^{20}$ a fourfold increase in ICP was observed. Because processes of water 


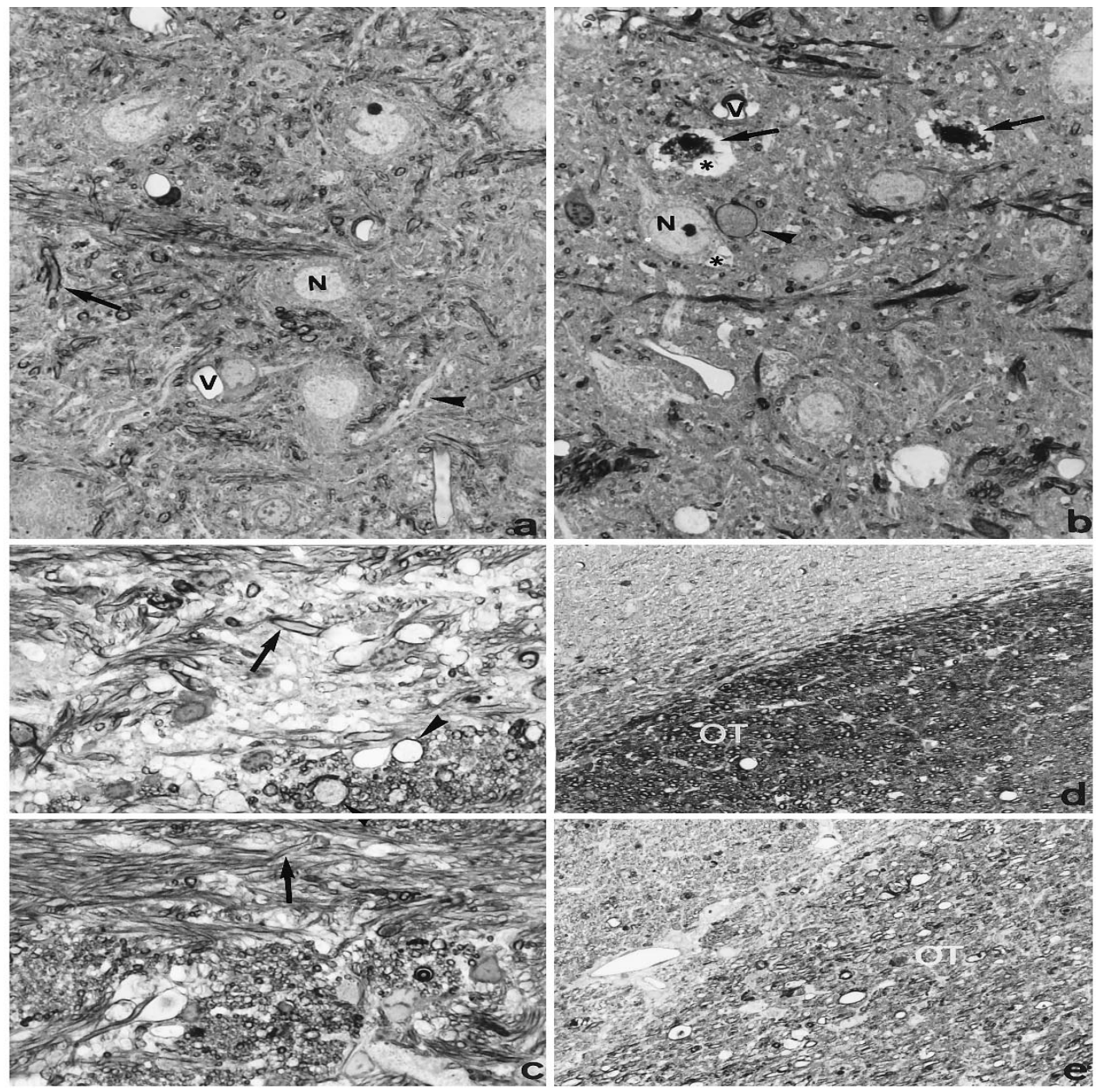

FIG. 8. Light microscopy studies of medial thalamic nucleus (a and b), internal capsule (c), and optical tract (d and e) in sham-injured rats ( $\mathrm{a}$ and d) and rats subjected to severe trauma that survived 4 hours (b), 24 hours (c), and 72 hours (e). a: In nontraumatized brain, neurons (N) and microvessels (V) exhibit a normal morphological aspect. They are embedded in a compact neuropil composed of normal-shaped unmyelinated (arrowhead) and myelinated cell processes (arrow). b: Four hours postinjury, several neurons appear to be shrunken with pyknotic nuclei (arrows), whereas others are well preserved $(\mathrm{N})$. Microvessels appear slightly compressed by swollen glial cell processes, which are also found throughout the neuropil and around neurons (asterisks). A number of myelinated axons show typical ballooning (arrowhead). c: At 24 hours axonal ballooning is more pronounced, leading to a disorganized aspect of white matter. Next to well-preserved axons (arrows) many axons are extremely swollen and have lost their axonal content (arrowheads). $\mathrm{d}$ and e: White matter disorganization was also found after 72 hours (e) in the optic tract (OT) as a result of axonal ballooning and myelin disintegration, a phenomenon that is not seen in uninjured rats (d). Toluidine blue, original magnification $\times 800(\mathrm{a}-\mathrm{c}) ; \times 280(\mathrm{~d}$ and $\mathrm{e})$.

displacement from the intravascular compartment to the extra- and intracellular compartment are relatively slow phenomena, they can hardly be responsible for the instantaneous increase in ICP. We suggest that immediately after head trauma, a vascular-mediated response may cause this instantaneous increase. At the moment of impact, the applied pressure wave causes a sudden cessation of all electrical activity in the brain..$^{20,24}$ Because arteries under normal conditions are in a state of semicontraction, a loss of vascular tonus, that is, vasoparalysis, will cause a CPPdriven dilation of these cerebral arteries. Such dilation in turn induces an increase in cerebral blood volume that cannot be compensated for by a rapid cerebrospinal fluid transfer or by an autoregulation-mediated vasoconstriction because the autoregulation is impaired. As a consequence, not only will ICP rise, but an increased transmural pressure may also compromise the stability of the blood-brain barrier. In addition, the latter may be aggravated by a blockade of the venous outflow, which will inevitably lead to extravasation. Transient leaks in the blood-brain barrier have been demonstrated recently on magnetic resonance imaging in the Marmarou impactacceleration model. ${ }^{1,11}$ From the moment vascular tonus begins to be restored, ICP will gradually decline toward a relatively stable pathological value. At later times, the relative contribution of vasoparalysis in sustaining patholog- 


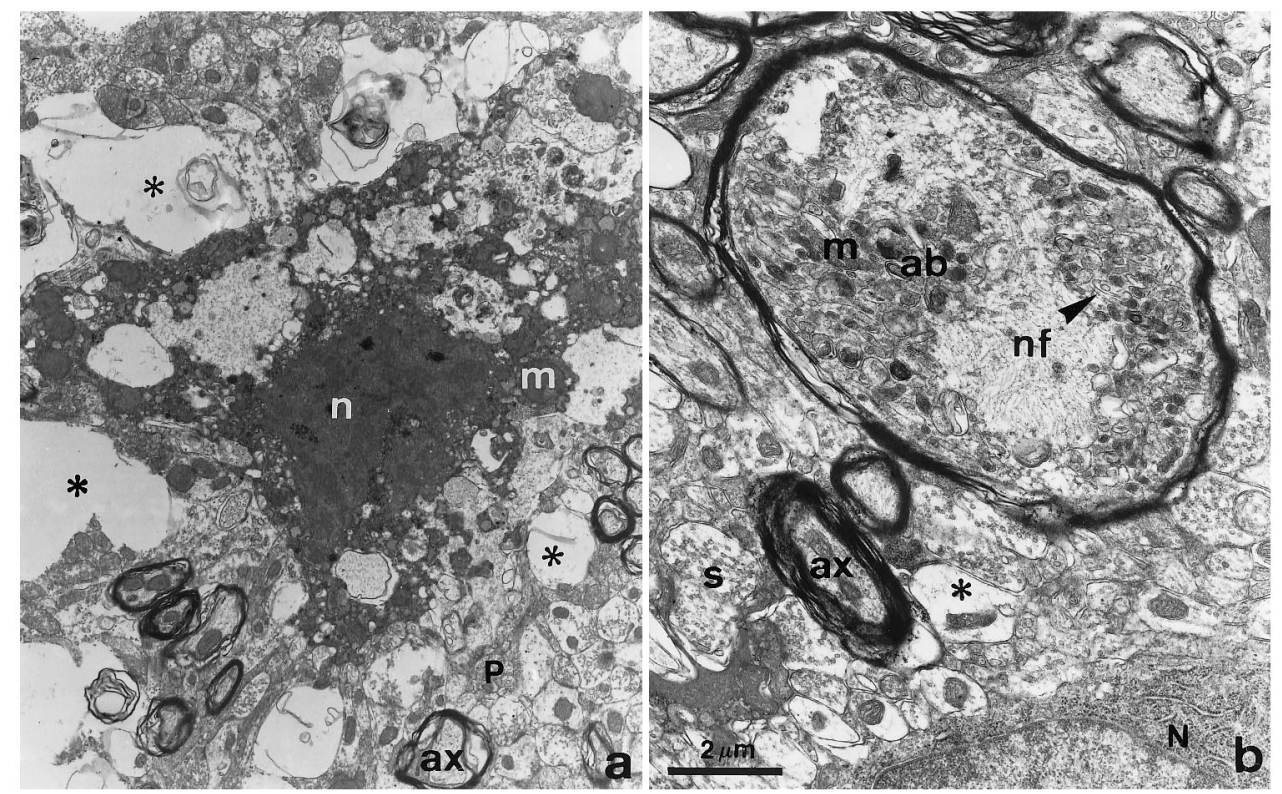

FIG. 9. Electron micrographs from medial thalamic nucleus 4 hours after severe trauma. a: Neurons with a pyknotic nucleus (n) and a completely disorganized cytoplasm with dense mitochondria $(\mathrm{m})$ are seen. The surrounding neuropil is characterized by extremely swollen processes that are probably of glial origin (asterisks). Myelinized axons (ax) and nonmyelinized cell processes (p) are relatively well preserved. b: Axonal ballooning can be recognized by extremely dilated axons ( $\mathrm{ab}$ ) that contain a core of neurofilaments (nf) surrounded by a region with accumulations of vesicular material (arrowhead) and mitochondria. Surrounding neurons (N), myelinized axons, and synapses (s) are relatively well preserved, whereas glial cell processes appear swollen (asterisk). Original magnification $\times 8000$.

ical ICP might diminish. However, because of progressive edematous brain swelling, the net ICP remains high.

\section{Conclusions}

With this modified experimental model of closed head injury, it is possible to produce a reliable, predictable, and reproducible pathological ICP with a limited number of skull fractures and low mortality rate. The ICP changes correlate linearly with the traumatic challenge, and pathological levels are reached rapidly after impact-acceleration trauma. It is suggested that the main contributors to acute ICP increase are congestive edema resulting from arterial vasoparalysis and/or venous constriction, whereas the more permanent pathological results are explained by progressively developing cellular edema. Histological examination for prolonged survival periods is indicative of irreversible neuronal necrosis, DAI, petechial bleeding, glial swelling, and perivascular edema. Because the model allows variations in the balance between impact and acceleration forces and mimics several major clinical features, it can be regarded as a valuable tool to study the complex pathophysiological cascade of TBI as well as to investigate pharmacotherapeutic interventions.

\section{Acknowledgments}

The authors express their appreciation to the following colleagues: Mr. Stan Eyckens and Mr. Raymond Broeckx for technical support; Mr. Mark Haseldonckx for continuing laboratory experience and advice; Professor Fons Sauren for supervising the biomechanical analysis of the model; Mr. Lambert Leijssen for preparing the illustrations; and Mr. Luc Wouters for performing the statistical analyses.

\section{References}

1. Barzó P, Marmarou A, Fatouros P, et al: Magnetic resonance imaging-monitored acute blood brain barrier changes in experimental traumatic brain injury. J Neurosurg 85:1113-1121, 1996

2. Bullock R, Chesnut RM, Clifton G, et al: Guidelines for the management of severe head injury. J Neurotrauma 13: 643-734, 1996

3. Cortez SC, McIntosh TK, Noble LJ: Experimental fluid percussion brain injury: vascular disruption and neuronal and glial alterations. Brain Res 482:271-282, 1989

4. Dixon CE, Lighthall JW, Anderson TE: Physiologic, histopathologic and cineradiographic characterization of a new fluid-percussion model of experimental brain injury in the rat. $\mathbf{J}$ Neurotrauma 5:91-104, 1988

5. Dixon CE, Lyeth BG, Povlishock JT, et al: A fluid percussion model of experimental brain injury in the rat. J Neurosurg 67: 110-119, 1987

6. Engelborghs K, Verlooy J, Van Reempts J, et al: Intracranial pressure in a modified experimental model of closed head injury. Acta Neurochir Suppl 70:123-125, 1997

7. Foda MAAE, Marmarou A: A new model of diffuse brain injury in rats. Part II: Morphological characterization. J Neurosurg 80:301-313, 1994 


\section{K. Engelborghs, et al.}

8. Gennarelli TA: Animate models of human head injury. J Neurotrauma 11:357-368, 1994

9. Gennarelli TA, Thibault LE, Adams JH, et al: Diffuse axonal injury and traumatic coma in the primate. Ann Neurol 12: 564-574, 1982

10. Goldstein M: Traumatic brain injury: a silent epidemic. Ann Neurol 27:327, 1990

11. Ito J, Marmarou A, Barzó P, et al: Characterization of edema by diffusion-weighted imaging in experimental traumatic brain injury. J Neurosurg 84:97-103, 1996

12. Lewis SB, Finnie JW, Blumbergs PC, et al: A head impact model of early axonal injury in the sheep. J Neurotrauma 13:505-514, 1996

13. Lighthall JW, Anderson TE: In vivo models of experimental brain and spinal cord trauma, in Salzman SK, Faden IA (eds): The Neurobiology of Central Nervous System Trauma. New York: Oxford University Press, 1994, pp 3-11

14. Marmarou A, Foda MAAE, van den Brink W, et al: A new model of diffuse brain injury in rats. Part I: Pathophysiology and biomechanics. J Neurosurg 80:291-300, 1994

15. Marshall LF, Marshall SB, Klauber MR, et al: The diagnosis of head injury requires a classification based on computed axial tomography. J Neurotrauma Suppl 1:S287-S292, 1992

16. McIntosh TK, Nobel L, Andrews B, et al: Traumatic brain injury in the rat: characterization of a midline fluid-percussion model. Cent Nerv Syst Trauma 4:119-134, 1987

17. Ommaya AK, Gennarelli TA: Cerebral concussion and traumatic unconsciousness. Correlation of experimental and clinical observation on blunt head injuries. Brain 97:633-654, 1974
18. Ommaya AK, Rockoff SD, Baldwin M: Experimental concussion. J Neurosurg 21:249-264, 1964

19. Paxinos G, Watson C: The Rat Brain in Stereotaxic Coordinates, ed 2. Sydney: Academic Press, 1986

20. Pfenninger EG, Reith A, Breitig D, et al: Early changes of intracranial pressure, perfusion pressure, and blood flow after acute head injury. Part 1: an experimental study of the underlying pathophysiology. J Neurosurg 70:774-779, 1989

21. Piper IR, Thompson D, Miller JD: Monitoring weight drop velocity and foam stiffness as an aid to quality control of a rodent model of impact acceleration neurotrauma. J Neurosci Methods 69:171-174, 1996

22. Shima K, Marmarou A: Evaluation of brain-stem dysfunction following severe fluid percussion head injury to the cat. $\mathbf{J}$ Neurosurg 74:270-277, 1991

23. Stalhammar D, Gralinat BJ, Allen AM, et al: A new model of concussive brain injury in the cat produced by extradural fluid volume loading. Brain Inj 1:93-112, 1987

24. Yoshino E, Yamaki T, Higuchi T, et al: Acute brain edema in fatal head injury: analysis by dynamic CT scanning. J Neurosurg 63:830-839, 1985

Manuscript received February 9, 1998

Accepted in final form June 22, 1998

Address reprint requests to: Koen Engelborghs, M.D., Department of Neurosurgery, University Hospital Antwerp, Wilrijkstraat 10, B-2650, Edegem, Belgium. 